\title{
BAJTÍN Y LA TEORÍA DE LA HISTORIA LITERARIA: EL CASO DE LA PICARESCA
}

\author{
Fernando Cabo Aseguinolaza
}

(Universidad de Santiago de Compostela)

Desde la consagración de Bajtín como una referencia insoslayable de la reflexión teórica a partir de mediados de los años setenta, se han ido consolidando muy distintas dimensiones de su presencia intelectual al socaire del progresivo y azaroso acceso a sus escritos. Se ha visto en él una figura clave para el desarrollo de una semiótica social que habría de fundarse en su translingüística. De manera muy llamativa, su nombre ha sido esgrimido en la confusión derivada de la crisis de fe formalista e inmanentista, y no sólo con una orientación pragmatizante. Algunas de sus categorías - heterología, dialogismo, cronotopo...- son hoy lugares comunes, casi malillas, en los estudios literarios, desde la narratología al análisis estilístico. En el marco de los estudios culturales, sus concepciones de la cultura popular, de la risa o del carnaval constituyen el principal acicate de un sinfín de estudios y reflexiones...

$Y$ sin embargo con frecuencia queda en un segundo término la circunstancia de que muchas de las formulaciones más asendereadas tienen su plasmación - aunque quizá no su origen último- en una arti- 
culación historiográfica muy definida que constituye un aspecto sustancial de su configuración teórica, sobre todo en la medida en que ésta se identifica -en los años treinta - con una teoría de la novela. Ello permite reclamar para Bajtín un lugar destacado en la Teoría de la historia literaria, puesto que, forzando un tanto las cosas, cabe afirmar que su teoría de la novela se halla en relación de interdependencia con una teoría subyacente de la historia literaria, que, por el contrario de la primera, tiene una presencia sólo tácita en sus escritos ${ }^{1}$.

Los trabajos centrales en este sentido - La poética de Dostoievski, la mayor parte de los estudios incluidos en Teoría y estética de la novela , las notas del trabajo dedicado al Bildungsroman...- implican inextricablemente teoría e historia de la novela. Y la razón de ello no radica -nótese bien- en el hecho de que la novela sea para Bajtín una noción histórica; más bien ocurre que la ahistoricidad última del concepto de novela determina una teoría de la historia sub specie novelística, y por tanto ancilar con respecto a la petición de principio teórica implicada en la concepción de la novela que Bajtín desarrolla de modo primordial en los trabajos aludidos.

La novela es para Bajtín antes un principio cualitativo que una forma literaria definida históricamente. Puede también decirse que, en la línea de la tradición romántica en la que se inscribe ${ }^{2}$, la novela es la plasmación de una entidad poética absoluta, que en su caso se identifica con la plenitud de la palabra dialógica. Y en tal sentido la novela se convierte, como asegura J.M. Schaeffer (1983: 92), en «plus qu'un objet littéraire courant». Porque, en efecto, la novela, como entidad absoluta, es irreductible a cualquier manifestación concreta. En «Épica y novela», por mencionar apenas un caso, la contraposición entre ambas formas literarias concluye con la afirmación de que «el proceso

1 M. Holquist (1990: 108) ha llegado a decir, sin coincidir plenamente con lo que aquí se sugiere, que el «dialogismo» en lo que pueda tener de teoría literaria «is perhaps best grasped as a historical poetics».

2 Es de mucho interés el prestar atención a la progenie teórica hacia la que el propio Bajtín apunta. En «Épica y novela», se resaltan como de especial interés para el «proceso vivo de formación de la novela como género» nombres como los de Rousseau, Fielding, Wieland, Blankenburg y Hegel (Bajtín, 1975: 457). Y en «De la prehistoria de la palabra novelesca» añade a Huet, y sobre todo, a Schlegel y Novalis (Bajtín, 1975: 411). Estos dos últimos tienen sin duda mucha mayor relevancia de la que parece indicar esta cita al paso. No está de más el sugerir por ejemplo, la relación teórica de Bajtín con Lukács en virtud de esta ascendencia romántica común, que no sólo implica a Hegel. Una cuestión que merecería un desarrollo adecuado es, por ejemplo, la de las concomitancias y divergencias de las nociones de ironía, del Lukács de la Teoría de la novela, y de heterología, de Bajtín, en su relación con la idea de totalidad y en lo que implican respecto al vínculo entre épica y novela. Sobre todas estas cuestiones es fundamental el trabajo de J. M. Schaeffer (1983). 
de formación de la novela no ha acabado» (Bajtín, 1975: 485). Aun cuando se la identifique con la expresión por excelencia de la época moderna, predomina su inacabamiento esencial, el cual parece ser, por tanto, mucho más que un mero rasgo coyuntural propio de una forma que se halla aún en pleno desarrollo o que mantiene en plenitud su vigencia. Sólo de este modo adquiere sentido la capacidad de la novela para subvertir el orden genérico tradicional y la radical excentricidad que con respecto a la literatura como conjunto orgánico se le atribuye.

Es así también como su estudio histórico se convierte en una empresa imposible, de modo que no sorprende en absoluto el encontrarse con la sustitución subrepticia, e inevitable, de la novela por la «novelidad»-la novelness, en palabra de G.S. Morson y C. Emerson- como objeto de una «poética histórica» (acuñación ésta que introduce Bajtín en el subtítulo de «Las formas del tiempo y del cronotopo en la novela»). Y la «novelidad» no es tanto la cualidad abstracta que hace de una novela lo que es, según parecen pensar Morson y Emerson, como un devenir indefinido con algunos momentos culminantes y representaciones especialmente felices: Cervantes, el Bildungsroman, Dostoievski... Éstas y aquéllos remiten -y tampoco de forma necesariaa géneros novelescos y novelas, pero no son la Novela, entidad que como tal es ajena a la historia (M. Holquist, 1990: 72).

Esta disociación conceptual, que constituye a juicio de Schaeffer un paralogismo y que podría entenderse también como una forma particularmente escurridiza de homonimia, tiene repercusiones muy notables desde el punto de vista de la Teoría de la historia literaria. Una de las más destacables apunta a la orientación teleológica que caracteriza un modelo historiográfico que adopta como protagonista de su relato una entidad concebida al tiempo como horizonte del desarrollo histórico y como principio cualitativo subyacente en sus manifestaciones más conspicuas (¿canónicas?), sean éstas los diálogos socráticos, la sátira menipea o los distintos géneros novelísticos.

La noción de novela remite una vez más hacia un principio abstracto -la plenitud dialógica de la palabra-, que se hace particularmente palmario, dejando a un lado ahora las relaciones entre los miembros del círculo de Bajtín, en algunas páginas de El marxismo y la filosofía del lenguaje (V. N. Voloshinov, 1929: 160 y ss.). Pienso de modo particular en aquellas que se dedican a la interrelación a lo largo de la historia entre la palabra ajena y la autorial y que, de acuerdo con el predominio de una u otra, concluyen proponiendo la consideración de cuatro épocas, la última de las cuales significa la disolución completa 
del contexto autorial en favor del discurso ajeno ${ }^{3}$. En discrepancia con lo que ocurre en los textos firmados por Bajtín, no es aquí la novela como tal la que protagoniza el progresivo dominio sobre el ámbito literario, sino la palabra ajena, en el marco de la preocupación fundamental del texto de Voloshinov por la problemática enunciativa. Pero el paralelismo es diáfano, y permite entrever la justeza de la apreciación de que, a partir de los años treinta, la novela y el género - frente a la palabra ajena y las épocas de Voloshinov- se convierten en prismas por los que se filtran buena parte de los conceptos y preocupaciones anteriores de Bajtín (G. S. Morson y C. Emerson, 1990: 271). Esta circunstancia, junto con la impronta de la teorización romántica sobre la novela y hasta un cierto trasfondo religioso ${ }^{4}$, ayudan ciertamente a explicarse ese teleologismo que impregna la visión histórica que tan íntimamente se asocia a la teoría bajtíniana de la novela. Una visión histórica que se plasma en la traza de una narración «genética» en la que se asigna a cada una de las formas novelísticas un papel muy determinado, pero también muy diferente del que les corresponde en las historias literarias tradicionales.

Al lado del componente teleológico - eso sí, sutil y en extremo cautivador en la pluma de Bajtín-, hay que considerar el evidente monismo de la concepción historiográfica que estamos considerando. En buena parte, se trata de un rasgo que va aparejado con el anterior. La relevancia de la palabra dialógica, identificada con la novela, como protagonista en torno a la cual se configura el modelo historiográfico, o, de otro modo, la elección de la perspectiva histórica para fundamentar una muy específica concepción del concepto de novela, conducen casi por fuerza al monismo. Pero un monismo de tipo particular: no el tradicional de la Geistesgeschichte u otros modelos historiográficos cercanos, entre ellos el pergeñado por Voloshinov, que buscan atribuir «la totalidad de aspectos, porciones y pormenores de una sección temporal a un solo concepto» (C. Guillén, 1989: 123), sino uno más flexible y plural en apariencia, que, partiendo de una polaridad conceptual, da cuenta del triunfo de uno de sus aspectos sobre el otro sin renunciar a

3 Se trata de períodos o épocas eleáticos, en el sentido que da C. Guillén (1989: 121) al calificativo.

4 Sobre este asunto se impone la remisión a las consideraciones de K. Clark y M. Holquist (1984: 120 y ss.). Y curioso es también el traer a colación las consideraciones Sobre una lírica comunista que pudiera venir de Rusia, de Antonio Machado (Poesía y prosa, III, 1805), donde se ensalza el énfasis del cristianismo ortodoxo sobre la fraternidad y su rechazo radical del solus ipse en relación muy directa, por cierto, con la poética dialógica que esboza el autor de Los complementarios en otros lugares (C. Martínez Romero, 1990). 
la consideración de situaciones intermedias y de conflicto. Tal circunstancia, indubitable, ha llevado a algunos exégetas de Bajtín a contraponer los planteamientos del teórico ruso con los de Hegel y el primer Lukács, mucho más unitarios y progresivos en su conformación interna (M. Holquist, 1990: 75).

Ocurre, sin embargo, que, en última instancia, el triunfo se traduce en suplantación. Y, así, aunque se admiten dos grandes líneas en el desarrollo de la novela, ésta termina por identificarse sólo con una de ellas, con la que incorpora la heterología y el dialogismo. Y la otra, la monológica, ha quedado reducida al papel de trasfondo limitado a dejar que brille con mayor fulgor la peculiaridad heterológica del discurso novelístico: «La palabra novelesca sólo ha desarrollado todas las posibilidades estilísticas específicas, exclusivas de ella, en la segunda línea. La segunda línea ha revelado definitivamente las posibilidades de que dispone el género novelesco; en esta línea, la novela se ha convertido en lo que es hoy» (Bajtín, 1975: 229).

Así las cosas, la historia de la novela se convierte en prehistoria, como quiere C. Segre (1984: 62), y la delimitación de ésta en un acto de profecía retrospectiva (H. Broch, 1955: 305) dedicada a rastrear los atisbos parciales de una plenitud por venir. No es extraño, pues, que hayan surgido ciertas discrepancias en este sentido. Puede decirse incluso que, en el contexto de una recepción fundamentalmente acrítica de la obra de Bajtín, algunos de los principales, y también primeros, desacuerdos han surgido con respecto al papel concedido a la historia literaria en el sistema del teórico ruso. T. Todorov (1981: 118) califica como analítica la labor historiográfica de Bajtín por emplear una serie restringida de categorías para describir hechos históricos. J. M. Schaeffer (1983: 89 y ss.) profundiza en la herencia romántica de las concepciones bajtínianas y destaca la escisión profunda que separa la vertiente historiográfica de la teórica o, como también dice, programática. C. Segre (1984: 61), de otro lado, insiste en la subordinación de la historia con respecto a la teoría de la concepción de Bajtín, y aun considera que tanto una como otra se hallan al servicio de la crítica, como demostrarían los libros dedicados a Dostoievski y Rabelais.

Estos tres autores apuntan la cuestión clave, pero a mi juicio no aciertan a plantearla en términos adecuados. Más que de subordinación o escisión, habría que hablar de la interrelación profunda entre historia y teoría literarias. la una no se concibe al margen de la otra; y, de hecho, toda labor historiográfica implica una teoría del hecho literario, del mismo modo que toda concepción teórica tiene su traducción 
en los términos de una teoría de la historia literaria. Y estas conexiones resultan particularmente perceptibles en la obra de Bajtín: teleologismo y monismo son, en este caso, las consecuencias historiográficas de una concepción esencialista de la novela y de su absolutización como manifestación literaria por antonomasia de la época moderna.

La historiografía no define un ámbito autónomo con respecto a la teoría. De manera que el identificar la primera con una suerte de empiricidad pura sólo puede dar lugar a confusiones indeseables, las cuales explican, por otra parte, algunas de las carencias en que incurren ciertas críticas dirigidas a Bajtín. Altamente significativos resultan, por ejemplo, los comentarios de Todorov a propósito de la relación de géneros novelísticos que el teórico ruso utiliza en su esquema histórico del desarrollo de la novela. Su reiteración muy aproximada en trabajos distintos y el carácter abierto que sin duda posee esa relación, lejano de una sitematicidad rigurosa, le llevan a afirmar que las categorías genéricas manejadas no son consecuencia de la deducción a partir de algún principio abstracto, sino el resultado de «une donnée préalable» 5 . No hay nada que objetar en este sentido. Pero sí con respecto a las conclusiones ulteriores que Todorov (1981: 142-143) extrae de estas circunstancias y que afectan a la supuesta naturaleza del carácter previo de las formas genéricas:

\begin{abstract}
l'histoire a laissé un certain nombre d'oeuvres, lesquelles se sont grouppées, dans l'histoire également, selon un petit nombre de modèles. Il s'agit là d'une donnée empirique. Et le travail de Bakhtine ne consiste pas à établir des genres mais, les ayant trouvés, à les soumettre à l'analyse... La pratique de Bakhtine ne fait donc que confirmer son attachement à l'histoire analytique, et, au-delà, sa conception des études littéraires comme formant une partie de l'histoire.
\end{abstract}

La historia de la literatura y sus categorías parecen tener para Todorov la consideración de hechos empíricos previos a la teoría, y, en esa medida, de representantes de una "realidad literaria» que contraponer a la artificiosidad de las nociones teóricas. Sin duda esto dista de ser así. Y el caso de la novela picaresca, una de las formas novelísticas incorporadas al esquema historiográfico de Bajtín, lo ilustra con acep-

5 Es transparente la relación de estas afirmaciones de Todorov con sus conceptos de género histórico y teórico, y la toma de partido, en contraste con posiciones teóricas anteriores, que implican en favor del primero. No es el lugar de referirse a la polémica en torno a estas nociones, sin embargo las observaciones siguientes son aplicables a la puesta en evidencia de la «impostura» de los géneros históricos. 
table nitidez, además de sugerir algunas observaciones útiles para la Teoría de la historia literaria. Quizá la primera sorpresa en este sentido proceda del hecho de que la picaresca constituya, no obstante un aparente reconocimiento, poco más de un blind spot en la concepción diacrónica bajtíniana. Su papel, en efecto, es muy poco relevante, no se cuenta desde luego entre los géneros favorecidos en la trayectoria teleológica tan íntimamente ligada a la caracterización teórica del concepto de novela, y, además, algunas de las observaciones que se hacen con respecto a ella resultan sorprendentes desde una perspectiva hispánica.

Su presencia en los panoramas históricos que Bajtín traza es esporádica. En comparación con los comentarios correspondientes al diálogo socrático, a la novela sofística, a la sátira menipea, a los géneros autobiográficos, a la novela barroca francesa o al Bildungsroman, las menciones que se le dedican apenas pasan de meros apuntes. Es cierto que al mismo tiempo se le asigna —en «La palabra en la novela»- un papel capital en el comienzo de la segunda línea novelística, pero es un papel, por así decirlo, preparatorio de la «gran novela» heterológica posterior ${ }^{6}$. Además, las desconcertantes razones que justifican esta importancia acrecientan la sorpresa. Evitando los detalles, la novela picaresca figura, junto con la «gran novela barroca», entre los ascendientes fundamentales de la «nueva novela de aventuras». Pero, al tiempo, novela barroca y picaresca aparecen enfrentadas, puesto que, a la «palabra patética» de la primera, se opone una supuesta palabra alegre y desinhibida del pícaro - situado junto por junto con el tonto y el bufón-que de forma voluntaria malentiende la «Mentira patética» como medio de «engaño gracioso». Ello conduce a valorar la novela picaresca a partir de la novedad —única- que se le reconoce: la de situar la palabra de su héroe al margen de cualquier pathos retórico y, en consecuencia, en antagonismo con la que se identifica en «las biografías (glorificación, apología), en las autobiografías (autoglorificación, autojustificación), en las confesiones (arrepentimiento), en la retórica jurídica y política (defensa-acusación), en la sátira retórica (desenmascaramiento patético), etc.» (Bajtín, 1975: 211).

Lo desencaminado de tal punto de vista, al menos en lo que se refiere a las principales obras de la picaresca española, es tan patente, que no precisa abundamiento. Importa más el preguntarse por sus razones.

6 Las referencias son abundantes, aunque siempre superficiales, en los trabajos dedicados a la novela. Así ocurre, además de aquí, en el trabajo dedicado al concepto de cronotopo (1975: 237-409), en Problemas de la poética de Dostoievski o en sus apuntes sobre el Bildungsroman (1979a: 211-261), en donde se percibe siempre una coincidencia básica en los planteamientos. 
Y quizá éstas - que no pasan de hipótesis- sugieran algunos puntos de reflexión para la Teoría de la historia literaria como disciplina, al tiempo que ponen en evidencia ciertos rasgos del esquema historiográfico bajtíniano. Se me ocurren tres aspectos que, a través de su confluencia, dan cuenta en cierta medida del lugar tan peculiar que la novela picaresca ocupa en él.

El primero de ellos tiene que ver con el planteamiento teleológico que guía la asignación de distintos papeles a cada uno de los géneros y formas novelísticas históricas. De un modo más o menos inadvertido, a cada género le corresponde una función bien delimitada en la articulación narrativa histórica que se trama muy especialmente en «La palabra en la novela». Y ese papel delimita en muy alto grado los rasgos que van a ponerse de relieve en cada caso. Por lo que a la picaresca se refiere, le va a corresponder cubrir un hueco muy destacado en la réplica de la palabra patética, la cual se identifica fundamentalmente con la gran novela barroca ${ }^{7}$. Un género éste capital en la trayectoria de la novela de la primera línea. La integridad de la palabra patética va a encontrar su respuesta en el antipatetismo de las figuras emblemáticas del pícaro, el tonto y el bufón, surgidas del fondo de la cultura popular. Pero de los tres, sólo el pícaro admite la identificación con una tradición específica: la novela picaresca de aventuras. Por tanto, y arrastrada por la lógica interna del modelo historiográfico, la picaresca pasa a ocupar el lugar de «primera gran forma de la novela de la segunda línea» (M. M. Bajtín, 1975: 220) en virtud de un muy discutible carácter antipatético y antirretórico que se le atribuye a través de la identificación deductiva - a pesar de Todorov-con la figura predefinida del pícaro o, acaso, con la categoría dialogística correspondiente del «engaño gracioso».

El segundo aspecto que me interesa resaltar afecta a cuestiones relativas a la historia de la teoría literaria. Bajtín -como Lukács-es heredero de la gran tradición, esencialmente romántica, de la teoría de la novela que se construye como una teoría del Bildungsroman. De hecho, es a este último al que le va a corresponder ocupar un lugar casi

7 En este sentido debe considerarse, además de la indefinición notable del concepto mismo de pathos, la infundada tendencia por parte de Bajtín (1975:210) a la identificación del discurso patético con la palabra autorial y, consiguientemente, con la pérdida de la distancia entre autor y personaje. La peculiaridad del pícaro y de su presencia como narrador parecen convertirlo, en ese sentido, en un candidato idóneo para replicar al patetismo atribuido a otros géneros. No obstante, ello hace poca justicia a la capacidad patética de una voz construida como es la del pícaro; piénsese en el Lazarillo o el Guzmán. 
simétrico al ocupado en la primera línea por la novela barroca. Si ésta se identificaba con la idea de la prueba, aquélla va replicar con la de formación (M. M. Bajtín, 1979a: 225 y ss.); y el papel crucial desde el punto de vista histórico de la novela barroca en la primera línea será equivalente al desempeñado por la novela de formación en la segunda. Ello inevitablemente redunda en detrimento de la picaresca - mucho más explícito aún en el trabajo de Bajtín (1979a: 213-215) sobre el Bildungsroman-, que se ve relegada en esta distribución de papeles por razones de tradición teórica. Lo cual contrasta con la tradición de la historiografía literaria, sobre todo española, donde la noción de novela picaresca - de ahí su protagonismo-, se fragua en estricta confluencia con la propia idea de novela, y en la línea de un entendimiento de ésta próximo al de argumento retórico - frente a historia y fábula-; esto es, como una narración básicamente «realista» sobre hechos verosímiles (J. M. Pozuelo, 1988: 158 y ss.).

La tercera consideración apunta de lleno al carácter no empírico - de nuevo, a pesar de Todorov- de la picaresca como género. En el uso que de ella hace Bajtín, se trata de un género crítico (F. Cabo, 1992: 291 y ss.), que resulta, en consecuencia, inexplicable sin atender a procesos semióticos de transducción (L. Dolezel, 1990: 167 y ss.). La imagen de la picaresca que el teórico ruso utiliza no es concebible de no apreciar en ella, por ejemplo, la mediación interpretativa del roman comique francés; de las traducciones y adaptaciones de que fueron objeto los principales textos españoles en la Francia del XVII; e incluso de la apropiación nacional de la tradición española, como hace el propio Charles Sorel en su Bibliothèque Françoise. El sentido de esta compleja tarea transductora es relativamente claro en sus líneas generales; y una de ellas es la que lleva a morigerar la vileza y deshonor de los antecedentes familiares del protagonista, convertido a veces, si no en el hijo de un escudero elevado a la nobleza «malgré lui», como ocurre en el Gil Blas, al menos en alguien capaz de alcanzar la redención burguesa de una acomodada posición social, como sucede con Pablos en la traducción de La Geneste (A. Sanz Cabrerizo, 1993). El pícaro, así, admite un entendimiento mucho menos definido desde un punto de vista social y hace más comprensibles algunas de las observaciones de Bajtín. Observaciones sobre las que pesa también la recepción inglesa de la picaresca española, muchas veces realizada a través de la intermediación patente del roman comique francés ( $R$. Loretelli, 1984: 97 y ss.). En todo caso, siempre en la línea del aligeramiento "patético» de estas obras, favoreciendo lo anecdótico y simplificando al extremo desde una perspectiva retórica la posición discursiva del narrador 
protagonista. El ineludible peso retórico-patético de la palabra de los principales pícaros españoles queda de este modo preterido, y se hace posible sostener que el pícaro se halla «situado más allá de las categorías -esencialmente retóricas- que constituyen la base de la figura del héroe en la novela de prueba: más allá de todo juicio, de toda defensa o acusación, de la autojustificación y el arrepentimiento» (M. M. Bajtín, 1975: 221).

Desde los intereses de la Teoría de la historia literaria, estas circunstancias apenas esbozadas acaso contribuyan a mostrar la inconveniencia de suponer el ámbito de la historia como antagónico, o siquiera ajeno, del de la teoría. Y, por tanto, también la de ver en Bajtín una especie de empiricidad deturpada por prejuicios teóricos. En sus trabajos sobre la novela, historia y teoría son ámbitos interdependientes. La teoría se apoya en la historia, y ésta se articula en virtud de designios teóricos. La especial situación de la picaresca lo revela con suficiente nitidez, y permite atisbar además cómo la articulación entre una y otra se muestra conectada con determinadas tradiciones específicas del campo de estudio y con la complejísima conformación semiótica y cultural del conocimiento literario.

\section{Referencias bibliográficas}

Bajtín, M. M. (1975). Teoría y estética de la novela. Trad. H. S. Kriúkova y V. Cazcarra. Madrid: Taurus, 1989.

BaJtín, M. M. (1979a). Esthétique de la création verbale. Trad. A. Acouturier. París: Gallimard, 1984.

Bajtín, M. M. (1979b). Problemas de la poética de Dostoievski. Trad. T. Bubnova. México: F. C. E. 1986.

Broch, H. (1955). Poesía e investigación. Trad. R. Ibero. Barcelona: Barral, 1974.

Cabo Aseguinolaza, F. (1990). El concepto de género y la picaresca. Santiago de Compostela: Universidad de Santiago de Compostela.

Clark, K., y M. Holquist (1984). Mikhail Bakhtin. Cambridge (Mass.): The Belknap Press.

Dolezel, L. (1990). Occidental Poetics. Tradition and Progress. Lincoln y Londres: University of Nebraska Press.

Gulllén, C. (1989). Teorías de la historia literaria. Madrid: Espasa Calpe.

HolQuist, M. (1990). Dialogism. Bakhtin and his World. Londres y Nueva York: Routledge.

LORETELl, R. (1984). Da picaro a picaro. Le trasformazioni di un genere letterario dalla Spagna all'Inghilterra. Roma: Bulzoni. 
Martínez Romero, C. (1990). «De la otredad en la poética machadiana». En Antonio Machado hoy. Actas del Congreso internacional conmemorativo de la muerte de Antonio Machado, IV, 103-108. Sevilla: Alfar.

Morson, G. S., y C. EMERSON (1990). Mikhail Bakhtin. Creation of a Prosaics. Standford: Standford University Press.

Pozuelo, J. M. (1988). Del formalismo a la neorretórica. Madrid: Taurus.

SAnz Cabrerizo, A. (1993). «Ya soy otro: El Buscón en la Bibliotheque Bleue de Troyes». Dicenda 11, 285-306.

SCHAEFFER, J. M. (1983). La naissance de la littérature. La théorie esthétique du romantisme allemand. Paris: Presses de l'École Normale Supérieure.

SEGRE, C. (1984). "Quello che Bachtin non ha detto. Le origini medievali del romanzo». En Teatro e romanzo. Due tipi di comunicazione letteraria, 61-84. Turín: Einaudi.

Todorov, T. (1981). Mikhaïl Bakhtine. Le principe dialogique. París: Éditions du Seuil.

Voloshinov, V. N. (1929). El marxismo y la filosofía del lenguaje. Trad. T. Bubnova. Madrid: Alianza Universidad, 1992. 